\title{
Effective and Simple NaOH-Modification Method to Remove Methyl Violet Dye via Ipomoea aquatica Roots
}

\author{
Yie Chen Lu, ${ }^{1}$ Muhammad Raziq Rahimi Kooh $\mathbb{D}^{2}{ }^{2}$ Linda Biaw Leng Lim $\mathbb{D}^{1}$ \\ and Namal Priyantha $\mathbb{B}^{3,4}$ \\ ${ }^{1}$ Chemical Sciences Programme, Faculty of Science, Universiti Brunei Darussalam, Jalan Tungku Link, Gadong, Brunei Darussalam \\ BE1410 \\ ${ }^{2}$ Centre for Advanced Material and Energy Sciences, Universiti Brunei Darussalam, Jalan Tungku Link, Gadong, Brunei \\ Darussalam BE1410 \\ ${ }^{3}$ Department of Chemistry, Faculty of Science, University of Peradeniya, Sri Lanka \\ ${ }^{4}$ Postgraduate Institute of Science, University of Peradeniya, Peradeniya, Sri Lanka
}

Correspondence should be addressed to Muhammad Raziq Rahimi Kooh; raziq.kooh@ubd.edu.bn and Linda Biaw Leng Lim; lindabl.lim@yahoo.com

Received 14 August 2021; Revised 7 September 2021; Accepted 16 September 2021; Published 13 October 2021

Academic Editor: Senthil Kumar Ponnusamy

Copyright (c) 2021 Yie Chen Lu et al. This is an open access article distributed under the Creative Commons Attribution License, which permits unrestricted use, distribution, and reproduction in any medium, provided the original work is properly cited.

\begin{abstract}
In this study, a simple chemical modification was applied to a sustainable and abundantly available resource, kangkong root (KR), to remove methyl violet $2 \mathrm{~B}(\mathrm{MV})$ dye. The chemically modified adsorbent ( $\mathrm{NaOH}-\mathrm{KR})$ was obtained using $\mathrm{NaOH}$ solution treatment. Batch adsorption experiments were carried out to investigate the effects of $\mathrm{pH}$, ionic strength, contact time, adsorbent dosage, and initial dye concentration. A regeneration experiment was also carried out to assess the potential of reusability. The adsorption process was modelled using various kinetics and isotherm models, whereby the best-fitting models were evaluated by using the coefficient of determination $\left(R^{2}\right)$ and error functions. The Sips $\left(R^{2}=0.9714, \chi^{2}=0.16\right)$ and pseudo-second-order $\left(R^{2}=0.9996, \chi^{2}=0.007\right)$ models were identified to best represent the adsorption process. The Sips model predicted a maximum adsorption capacity at $551.5 \mathrm{mgg}^{-1}$ for $\mathrm{NaOH}-\mathrm{KR}$, which is $55 \%$ improvement in performance when compared to nonmodified KR. Lastly, the regeneration experiment showed that $\mathrm{NaOH}-\mathrm{KR}$ was able to maintain reasonable dye removal even after five consecutive cycles of regenerating and reusing.
\end{abstract}

\section{Introduction}

Pollution is the contamination of the natural ecosystem and environment either derived from human activities (e.g., transportation, agriculture, disposal of industrial wastes, and energy generation) or natural disasters (e.g., volcanic eruption and flooding) [1-4]. The population of the world is increasing at an alarming rate, with an estimated rise of more than 5 billion within the last century [5]. With the increase of the human population, the demand for potable water increases as well [6]. Because of the rise in human activities, there is a continuous discharge of industrial and agricultural wastes, which contain many pollutants, including synthetic dyes, pesticides, and heavy metals, into the nat- ural world and simultaneously give rise to environmental pollution [7].

In recent years, there is increased research in various methods of wastewater remediation to tackle the wastewater pollution problem [8]. Among these methods, adsorption remains the most preferred method to solve wastewater problems and is also effective in the removal of wastewater containing synthetic dyes and heavy metals [9]. It is simple to conduct and requires no sophisticated skill. Compared to other wastewater treatment methods, adsorption is relatively inexpensive since the selection of readily available low-cost raw materials as adsorbents can be used. Research in recent years has shown that various natural biomass adsorbents such as leaves $[9,10]$, agroindustrial wastes such 
as breadfruit peels, and spent soya bean pulp [11, 12], as well as synthetic adsorbents such as chemically modified dextran and magnetic nanoparticles [13-15], were found effective for treating wastewater. Despite the many reports available, the search for better, stable, more economical, and effective adsorbents is still of importance and in great demand.

Ipomoea aquatica (water spinach), belonging to the Convolvulaceae or bindweed family, is used as a popular vegetable culinary in Southeast Asian countries. Locally known as kangkong, it can be cultivated both on land and in shallow water. However, wild kangkong is found growing in shallow swamps, ditches, and fields due to its invasive nature. Kangkong is high in antioxidants [16], minerals (such as potassium and iron), fiber, and vitamin A [17]. Normally, the green leaves and tender parts of the vegetable are used in cooking, whereas the stem and root are thrown away as waste. In China [18] and Malaysia [19], kangkong has been successfully utilized in improving the quality of aquaculture wastewater. The plant also exhibits an ability to bioaccumulate contaminants such as antibiotics [20] and heavy metals such as lead [21] and chromium [22] but also to remove cadmium [23]. Phytoextraction of cadmium was achieved with the roots and stems [24] of kangkong. The use of kangkong as an adsorbent for wastewater remediation has been previously reported but mainly involved the use of its stem. The stems have also been used as an adsorbent to adsorb Auramine $\mathrm{O}$ [25] and methyl violet 2B (MV) [26] dyes and thermally treated to produce activated carbon which is useful for removing cationic dyes [27]. Moreover, the leaves were used for removing manganese [21], while the roots and stems were used for removing cadmium [23].

To date, the adsorption studies involving kangkong roots (KR) remain scarce, and limited literature showed the success of unmodified KR in removing Auramine $O$ [28] and MV [25] dyes from an aqueous solution.

$\mathrm{MV}$, a triphenylmethane cationic dye of intense colour, is also known as basic violet 1 dye. Even though the powdered form of MV dye is dark green in colour, it dissolves in water to give a solution of intense violet colour. These days, MV dye is widely used in textile, printing, inks, toners, leather, plastic, and rubber industries [29]. Besides these, MV can also be used as a biological stain and a moderateclass disinfectant. However, this dye is harmful to human health. MV has carcinogenic and mutagenic properties and is also a known irritant that can affect the eyes, skin, and gastrointestinal and respiratory tract [29]. MV also hinders the growth of microorganisms and prevents photosynthesis reactions from taking place in aquatic plants and animals in the environment [30].

The main aim of this study focuses on the use of KR, which has been subjected to chemical modification with $\mathrm{NaOH}$, to adsorb MV dye from an aqueous solution. The objectives of this study include investigating various parameters (contact time, $\mathrm{pH}$, initial dye concentration, and ionic strength) that affect the adsorption of MV dye. The characterisation of the adsorbent includes surface morphology and functional group analyses. The effect of temperature and regeneration experiments were also carried out.

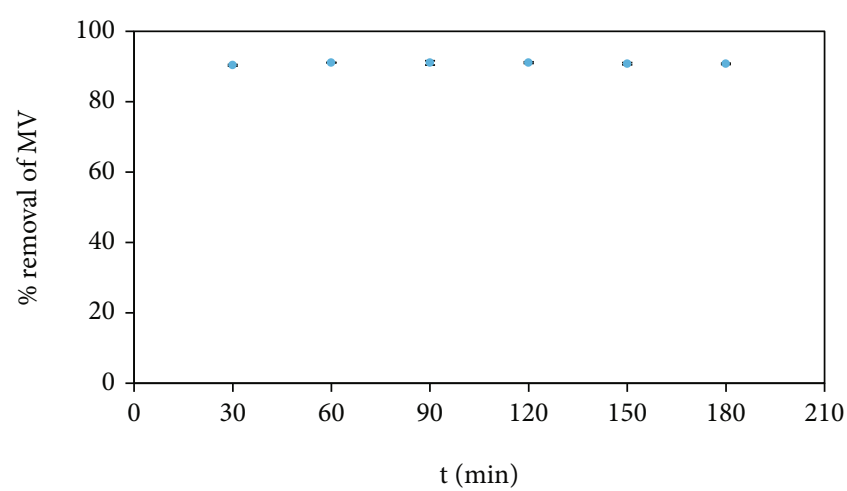

FIGURE 1: The effect of contact time on the removal of MV via $\mathrm{NaOH}-\mathrm{KR}$ (mass of adsorbent $=0.020 \mathrm{~g}$; volume of $\mathrm{MV}$ solution $=$ $10.0 \mathrm{~mL}$; concentration of $\mathrm{MV}=100 \mathrm{mg} \mathrm{L}^{-1}$ ).

\section{Materials and Methods}

2.1. Adsorbent Preparation. The kangkong plants were purchased from the local supermarket. Thereafter, the roots were harvested, washed under running water to remove dirt, and lastly washed with distilled water. The washed KR was oven-dried at $65^{\circ} \mathrm{C}$. The dried $\mathrm{KR}$ was ground into powder using a household kitchen blender. Dried KR powder $(50.0 \mathrm{~g})$ was placed in a $2000 \mathrm{~mL}$ beaker and mixed with $1 \mathrm{M} \mathrm{NaOH}(1000 \mathrm{~mL})$ solution and stirred using a magnetic stirrer at room temperature for 2 hours. After stirring, the $\mathrm{NaOH}$-modified $\mathrm{KR}(\mathrm{NaOH}-\mathrm{KR})$ was washed repeatedly with distilled water until the $\mathrm{pH}$ of the washed solution is near neutral. Lastly, the washed $\mathrm{NaOH}-\mathrm{KR}$ was dried in an oven at $65^{\circ} \mathrm{C}$ to a constant mass and stored in a desiccator.

2.2. Chemicals and Reagents. Methyl violet $2 \mathrm{~B}$ (MV) dye $\left(\mathrm{C}_{24} \mathrm{H}_{28} \mathrm{~N}_{3} \mathrm{Cl}\right.$, dye purity $75 \%, 393.95 \mathrm{~g} \mathrm{~mol}^{-1}$, Biological Stain Commission certified) was obtained from SigmaAldrich. Hydrochloric acid ( $\mathrm{HCl}$, Auburn USA), sodium hydroxide $(\mathrm{NaOH}$, Auburn USA), potassium nitrate $\left(\mathrm{KNO}_{3}\right.$, Merck $\mathrm{KGaA}$ Germany), and sodium chloride ( $\mathrm{NaCl}$, GPR USA) are all analytical reagent grade. A stock solution of MV dye (1000 $\left.\mathrm{m} \mathrm{L}^{-1}\right)$ was prepared, and other concentrations were obtained by further dilution. Spectroscopy grade potassium bromide $(\mathrm{KBr})$ crystals were used for the FTIR spectroscopy analysis and were dried in an oven at $100^{\circ} \mathrm{C}$ prior to use. Entire experiments were performed in duplicate unless otherwise stated.

2.3. Experimental Methodology. The batch adsorption experiments were carried out using adsorbent-adsorbate in the ratio of $1.0 \mathrm{~g}$ of sample: $500 \mathrm{~mL}$ of $100 \mathrm{mg} \mathrm{L}^{-1}$ dye solution, unless otherwise stated. Apart from that, all experiments were carried out in duplicates and were agitated at $250 \mathrm{rpm}$ at room temperature, except for thermodynamics studies where temperatures of $298 \mathrm{~K}, 313 \mathrm{~K}, 323 \mathrm{~K}, 333 \mathrm{~K}$, and $343 \mathrm{~K}$ were used.

Determination of the contact time required was performed by analyzing the filtrate from the adsorbentadsorbate mixtures at every 30-minute interval until equilibrium is reached. All subsequent experiments, except 


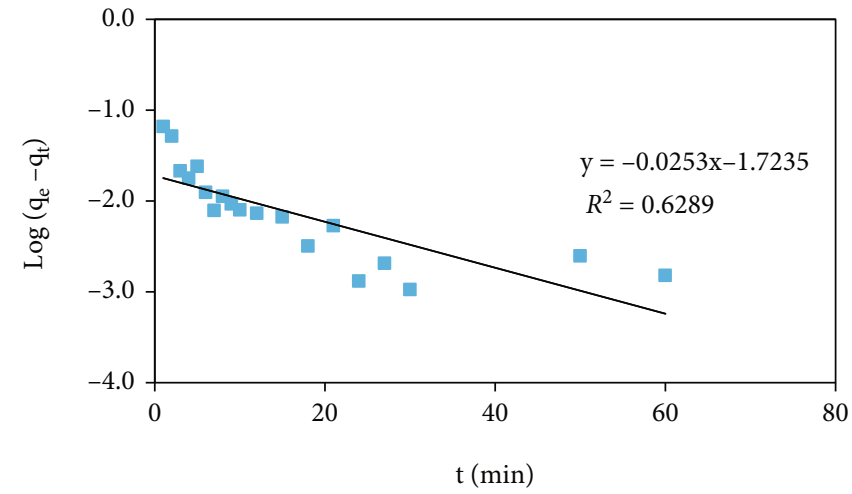

(a)

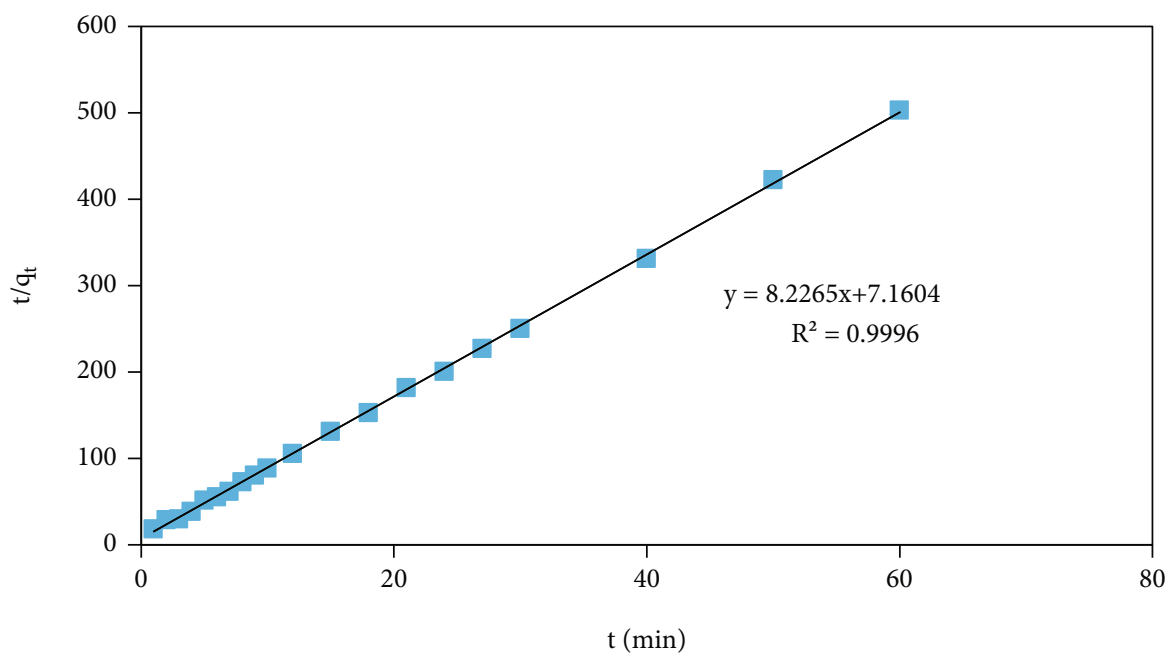

(b)

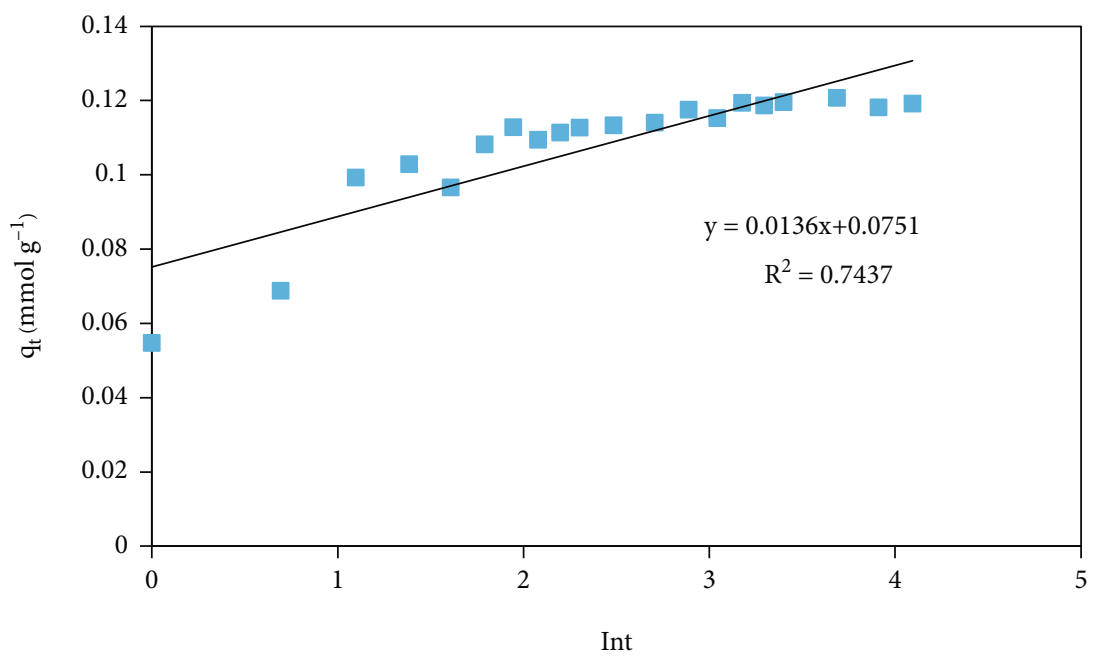

(c)

Figure 2: Continued. 


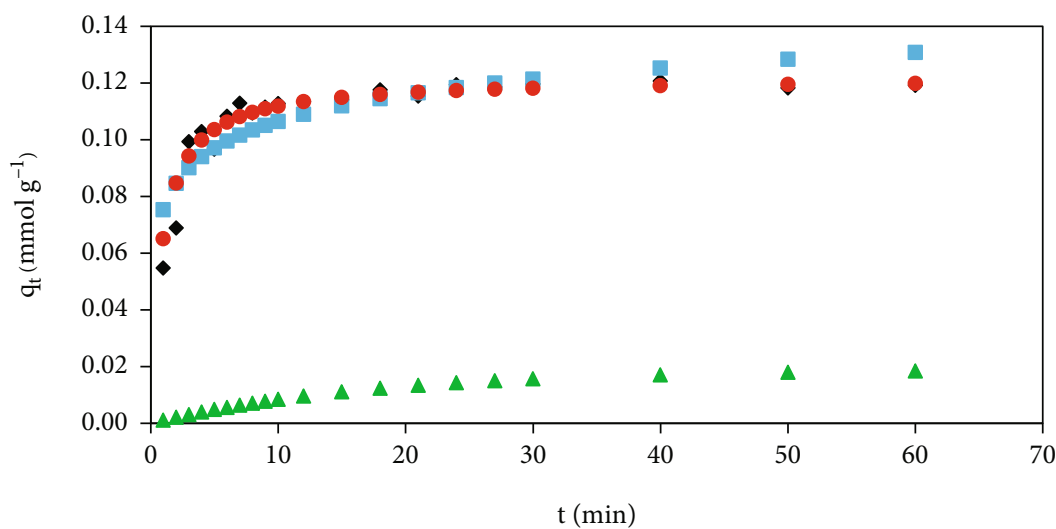

(d)

Figure 2: The linear plots of (a) pseudo-first-order, (b) pseudo-second-order, and (c) Elovich models and (d) comparison of kinetics simulation plots for the experimental data (black diamond), Elovich (blue square), pseudo-first-order (green triangle), and pseudosecond-order (red circle) models (mass of adsorbent $=0.020 \mathrm{~g}$; dye volume $=10.0 \mathrm{~mL}$; concentration of $\mathrm{MV}=100 \mathrm{mg} \mathrm{L}^{-1}$ ).

TABLE 1: Comparison of the pseudo-first-order, pseudo-second-order, and Elovich models and their error values of linear analyses.

\begin{tabular}{|c|c|c|c|c|c|c|}
\hline Kinetics model and parameters & Values & ARE & SSE & EABS & MPSD & $\chi^{2}$ \\
\hline Pseudo-first-order & & 91.471 & 0.195 & 1.958 & 96.520 & 1.785 \\
\hline$R^{2}$ & 0.6289 & & & & & \\
\hline$K_{1}\left(\min ^{-1}\right)$ & 0.058 & & & & & \\
\hline$q_{\mathrm{e}, \mathrm{expt}}\left(\mathrm{mmol} \mathrm{g}^{-1}\right)$ & 0.117 & & & & & \\
\hline$q_{\mathrm{e}, \mathrm{calc}}\left(\mathrm{mmol} \mathrm{g}^{-1}\right)$ & 0.019 & & & & & \\
\hline Pseudo-second-order & & 3.736 & 0.001 & 0.061 & 7.493 & 0.007 \\
\hline$R^{2}$ & 0.9996 & & & & & \\
\hline$K_{2}\left(\mathrm{~g} \mathrm{mmol} \mathrm{min}^{-1}\right)$ & 9.451 & & & & & \\
\hline$q_{\mathrm{e}, \mathrm{expt}}\left(\mathrm{mmol} \mathrm{g}^{-1}\right)$ & 0.117 & & & & & \\
\hline$q_{\mathrm{e}, \text { calc }}\left(\mathrm{mmol} \mathrm{g}^{-1}\right)$ & 0.122 & & & & & \\
\hline Elovich & & 7.421 & 0.001 & 0.135 & 11.943 & 0.018 \\
\hline$R^{2}$ & 0.7437 & & & & & \\
\hline$\alpha\left(\mathrm{mmolg}^{-1} \mathrm{~min}^{-1}\right)$ & 3.43 & & & & & \\
\hline$\beta\left(\mathrm{g} \mathrm{mmol}^{-1}\right)$ & 73.60 & & & & & \\
\hline
\end{tabular}

$K_{1}$ is the pseudo-first-order rate constant, $K_{2}$ is pseudo-second-order rate constant, while $q_{\mathrm{e}, \text { expt }}$ and $q_{\mathrm{e}, \text { calc }}$ represent the adsorption capacity at equilibrium obtained experimentally and those predicted by the kinetics models, respectively.

for kinetics, were carried out using the obtained contact time. Investigations of the $\mathrm{pH}$ and ionic strength effects on the adsorption of $\mathrm{MV}$ were performed with the $\mathrm{pH}$ ranging from 2 to 10, including the untreated (ambient) $\mathrm{pH}$, and $\mathrm{NaCl}\left(0-1.0 \mathrm{~mol} \mathrm{~L}^{-1}\right)$ was used as the salt for studying the effect of the ionic strength. All experiments were carried out in duplicate.

The adsorption capacity, $q_{\mathrm{e}}\left(\mathrm{mmol} \mathrm{L}^{-1}\right)$, and \% removal were calculated from the equations as follows:

$$
\begin{aligned}
q_{\mathrm{e}} & =\frac{\left(C_{\mathrm{i}}-C_{\mathrm{e}}\right) V}{M_{\mathrm{r}} \cdot m}, \\
\% \text { removal } & =\frac{\left(C_{\mathrm{i}}-C_{\mathrm{e}}\right) \cdot 100 \%}{C_{\mathrm{i}}},
\end{aligned}
$$

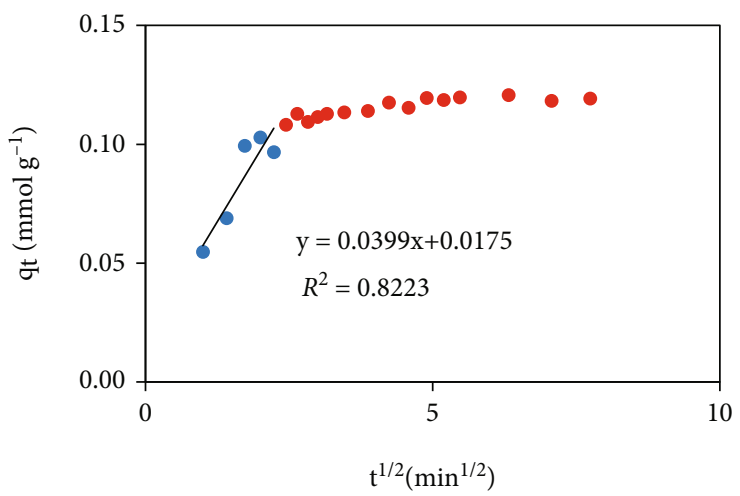

FIGURE 3: The linear plot of the Weber-Morris intraparticle diffusion model of MV adsorption (mass of adsorbent $=0.020 \mathrm{~g}$; volume of MV solution $=10.0 \mathrm{~mL}$; concentration of $\left.\mathrm{MV}=100 \mathrm{mg} \mathrm{L}^{-1}\right)$. 
TABLE 2: Adsorption isotherm models and their parameters.

\begin{tabular}{|c|c|c|c|c|c|c|}
\hline Model & Values & ARE & SSE & EABS & MPSD & $\chi^{2}$ \\
\hline Langmuir & & 21.10 & 0.05 & 0.72 & 27.83 & 0.15 \\
\hline$Q_{\max }\left(\mathrm{mmol} \mathrm{g}^{-1}\right)$ & 1.163 & & & & & \\
\hline$Q_{\max }\left(\mathrm{mgg}^{-1}\right)$ & 457.99 & & & & & \\
\hline$K_{\mathrm{L}}\left(\mathrm{L} \mathrm{mmol}^{-1}\right)$ & 0.009 & & & & & \\
\hline$R^{2}$ & 0.9053 & & & & & \\
\hline Freundlich & & 22.13 & 0.36 & 1.34 & 28.67 & 0.50 \\
\hline$K_{\mathrm{F}}\left(\mathrm{mmolg}^{-1}\left(\mathrm{~L} \mathrm{mmol}^{-1}\right)^{1 / n}\right)$ & 0.017 & & & & & \\
\hline$K_{\mathrm{F}}\left(\mathrm{mg}^{1-1 / n} \mathrm{~L}^{1 / n} \mathrm{~g}^{-1}\right)$ & 6.649 & & & & & \\
\hline$n$ & 1.362 & & & & & \\
\hline$R^{2}$ & 0.9656 & & & & & \\
\hline Temkin & & 196.66 & 0.24 & 1.86 & 446.00 & 5.70 \\
\hline$K_{\mathrm{T}}\left(\mathrm{L} \mathrm{mmol}^{-1}\right)$ & 0.320 & & & & & \\
\hline$b_{\mathrm{T}}\left(\mathrm{kJ} \mathrm{mol}^{-1}\right)$ & 14.533 & & & & & \\
\hline$R^{2}$ & 0.8726 & & & & & \\
\hline Redlich-Peterson & & 21.81 & 0.31 & 1.25 & 29.24 & 0.43 \\
\hline$K_{\mathrm{R}}\left(\mathrm{Lg}^{-1}\right)$ & 0.040 & & & & & \\
\hline$n_{\mathrm{R}}$ & 0.333 & & & & & \\
\hline$a_{\mathrm{R}}\left(\mathrm{L} \mathrm{mmol}^{-1}\right)$ & 1.504 & & & & & \\
\hline$R^{2}$ & 0.7937 & & & & & \\
\hline Sips & & 19.79 & 0.06 & 0.76 & 28.14 & 0.16 \\
\hline$Q_{\max }\left(\mathrm{mmolg}^{-1}\right)$ & 1.400 & & & & & \\
\hline$Q_{\max }\left(\mathrm{mgg}^{-1}\right)$ & 551.54 & & & & & \\
\hline$K_{\mathrm{S}}\left(\mathrm{L} \mathrm{mmol}^{-1}\right)$ & 0.010 & & & & & \\
\hline$N$ & 1.090 & & & & & \\
\hline$R^{2}$ & 0.9714 & & & & & \\
\hline
\end{tabular}

where $C_{\mathrm{i}}$ is the initial adsorbate concentration $\left(\mathrm{mg} \mathrm{L}^{-1}\right), C_{\mathrm{e}}$ is the concentration of adsorbate in the aqueous solution at equilibrium $\left(\mathrm{mg} \mathrm{L}^{-1}\right), V$ is the volume of adsorbate $(\mathrm{mL})$, $m$ is the adsorbent mass $(\mathrm{g})$, and $M_{\mathrm{r}}$ is the molecular mass $\left(\mathrm{molg}^{-1}\right)$.

2.4. Error Function. The adsorption process is characterized using various kinetics and isotherm models, whereby the linear variant of the models that best fitted with the experimental data is usually determined using the coefficient of determination $\left(R^{2}\right)$. Additionally, five error functions: average relative error (ARE), sum of square error (SSE), sum of absolute error (EABS), Marquardt's percent standard deviation (MPSD), and nonlinear chi-square error $\left(\chi^{2}\right)$, as listed in Table S1, are used to further reinforce the suitability of these models.

2.5. Instrumentation. The concentrations of MV were determined using the Shimadzu UV-1601 PC spectrophotometer (UV-vis), at $\lambda_{\max } 584 \mathrm{~nm}$. The surface morphology analysis of the adsorbent was carried out using the Quanta 400 FEI, scanning electron microscopy (SEM), Czech Republic. The functional group analysis was carried out using the Shimadzu IRPrestige-21 Fourier-transform infrared spectroscopy (FTIR). In addition, the Stuart orbital shaker (UK) was used for agitation of the adsorbent-adsorbate mixture at an agitation speed of $250 \mathrm{rpm}$. The thermodynamics studies were carried out using the Bibby Scientific Stuart shaker (UK), and water bath was adjusted to the desired temperature accordingly. The Mettler Toledo balance (Switzerland) was used to weigh the samples and chemicals. Measurement of the $\mathrm{pH}$ was done using the GP $353 \mathrm{pH}$ meter, UK.

\section{Results and Discussion}

3.1. Effect of Contact Time on MV Dye Removal. NaOH-KR adsorption equilibrium toward MV was achieved within 60 minutes (Figure 1), which was much faster than the untreated KR and other reported adsorbents such as $N$-benzyltriazole derivatized dextran [13] and modified Ceiba pentandra sawdust [31] with a reported contact time of 120 and 90 minutes, respectively, while longer equilibrium time for maleic anhydride-modified cellulose fibers/diatomite (200 minutes) [32].

3.2. Kinetics Studies. The kinetics data were modelled with the pseudo-first-order [33], pseudo-second-order [34], and Elovich [35] models. These models have been widely reviewed [36-38], and their linear and nonlinear equations are listed in Table S2. The suitability of the best fit model 


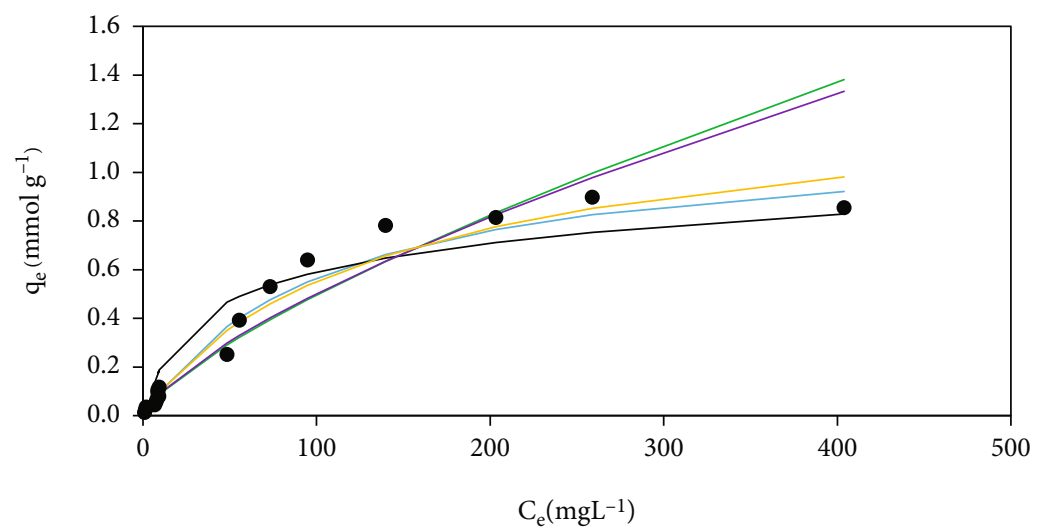

FIGURE 4: Simulation plots of Langmuir (blue line), Freundlich (green line), Temkin (black line), R-P (purple line), and Sips (yellow line) compared with the experimental data (black circle) obtained (mass of adsorbent $=0.020 \mathrm{~g}$; volume of $\mathrm{MV}$ solution $=10.0 \mathrm{~mL}$; concentration of $\mathrm{MV}=0$ to $\left.1000 \mathrm{mg} \mathrm{L}^{-1}\right)$.

for the adsorption kinetics was evaluated based on the following criteria, namely, the model with the highest $R^{2}$, the lowest overall error values, the closeness of the experiment data to the simulation plots, and comparison of the calculated adsorption capacity $\left(q_{\mathrm{e}, \mathrm{calc}}\right)$ with the obtained experimental $\left(q_{\mathrm{e}, \text { expt }}\right)$. From the linear plots of the three kinetics models, the pseudo-second-order model as shown in Figure 2(b) has $R^{2}$ close to unity. Both the pseudo-firstorder and Elovich models have $R^{2}$ values of $<0.75$ (Figures 2(a) and 2(c)), while Figure 2(d) clearly ruling out the former model as it showed a large deviation from the experimental data. Furthermore, the pseudo-first-order model showed very high error values (Table 1) when compared to the other models. Although the Elovich model appears to be close to the experimental data in Figure 2(d), nevertheless, its low $R^{2}$ coupled with higher error values, when compared to the pseudo-second-order model, indicate that it is also an unsuitable model for the adsorption of MV onto $\mathrm{NaOH}-\mathrm{KR}$.

Furthermore, as observed in Figure 3, the Weber-Morris plot displayed multilinearity behavior. The first linear region indicates the intraparticle diffusion, while the second linear region indicates the slow equilibrium phase [30]. As the intercept of the first linear region of the Weber-Morris plot is not zero, this suggests that intraparticle diffusion is not the rate-controlling step.

3.3. Adsorption Isotherm. A batch adsorption isotherm study was performed, and the data obtained were analyzed using five isotherm models, namely, Langmuir [39], Freundlich [40], Temkin [41], Redlich-Peterson [42], and Sips [43]. Their equations are as shown in Table S3. These models have been widely reviewed [38, 44]. All experiment isotherm data points to the Sips model being the best fit model to describe the adsorption of MV onto the based treated adsorbent. Based on the results obtained from Table 2, the Redlich-Peterson model has the lowest $R^{2}$, and further confirmation of the unsuitability of the RedlichPeterson model is from Figure 4, which clearly shows that this model very much deviated from the experimental data.
TABLE 3: Comparison of the $Q_{\max }$ values of reported adsorbents.

\begin{tabular}{lcc}
\hline Adsorbent & $\begin{array}{c}Q_{\text {max }} \\
\left(\mathrm{mgg}^{-1}\right)\end{array}$ & Reference \\
\hline NaOH-KR & 551.5 & This study \\
KR & 354.6 & {$[25]$} \\
Ipomoea aquatica stem & 267.9 & {$[26]$} \\
Cu/Al layered double hydroxide & 361.0 & {$[47]$} \\
Rock melon skin & 224.6 & {$[48]$} \\
NaOH-treated rock melon skin & 669.7 & {$[48]$} \\
Acid-modified coal-based activated carbon & 83.3 & {$[49]$} \\
Cempedak durian & 238.7 & {$[50]$} \\
Surfactant-modified Fe ${ }_{3}$ H $_{4}$ magnetic & 416.7 & {$[14]$} \\
nanoparticles & 139.7 & {$[45]$} \\
Artocarpus odoratissimus leaves & 1004.3 & {$[45]$} \\
NaOH-treated A. odoratissimus leaves & 7.3 & {$[51]$} \\
Acid-modified Saccharum bengalense & 43.7 & {$[52]$} \\
Unfunctionalized cellulose & 106.4 & {$[52]$} \\
Functionalized cellulose & 104.2 & {$[53]$} \\
Cinnamomum camphora fallen leaf powder & 206.6 & {$[54]$} \\
NaOH-modified C. camphora leaf powder & 6.7 & {$[55]$} \\
Water hyacinth & 30.6 & {$[56]$} \\
Sapindus mukorossi (reetha) pericarp & 202.8 & {$[57]$} \\
Granulated mesoporous carbon & 194.0 & {$[30]$} \\
Nepenthes rafflesiana leaves & 248.2 & {$[58]$} \\
Pomelo leaves & 910.8 & {$[58]$} \\
NaOH-treated pomelo leaves & 95.2 & {$[13]$} \\
N-Benzyltriazole derivatized dextran & 267.6 & {$[59]$} \\
Water lettuce & 194.2 & {$[29]$} \\
Azolla pinnata & 307.0 & {$[11]$} \\
Breadfruit core & & {$[32]$} \\
Maleic anhydride-modified cellulose & & \\
fibers/diatomite & & \\
\hline
\end{tabular}

Even though the $R^{2}$ value of the Freundlich model was high, but by reason of its simulation plot being very much deviated from the experimental data, as shown in Figure 4, 


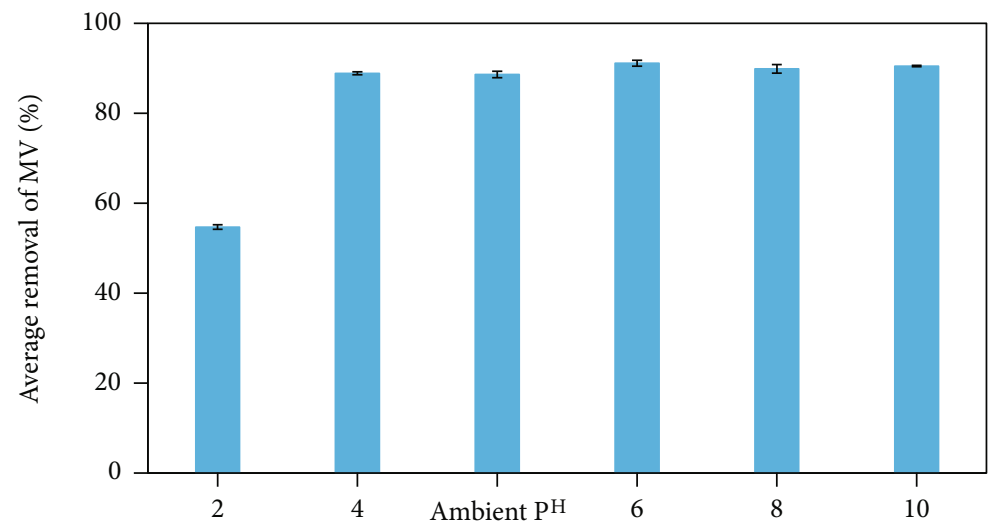

(a)

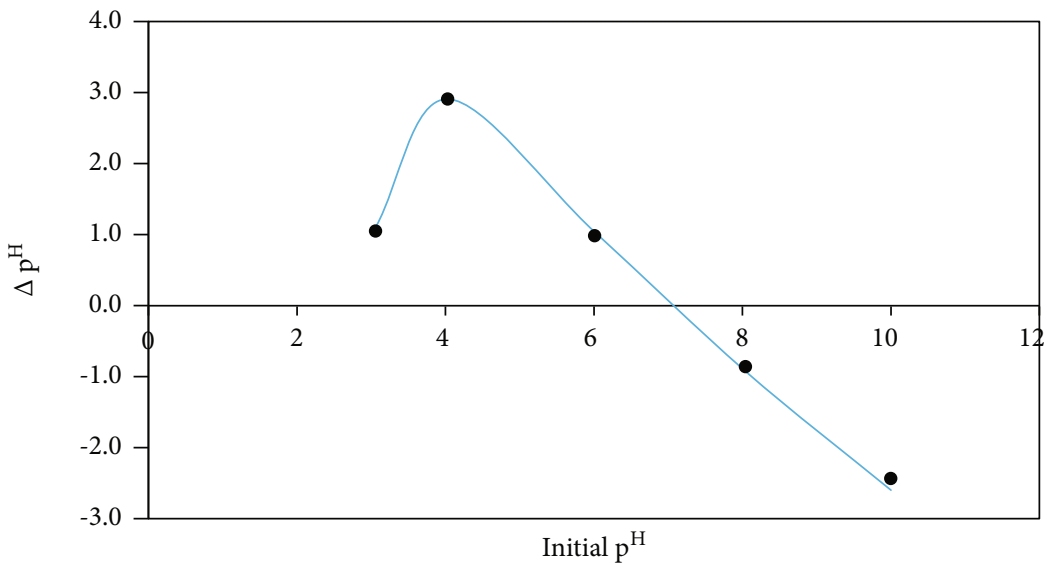

(b)

Figure 5: (a) The effect of $\mathrm{pH}$ on adsorption of MV and (b) Determination of $\mathrm{pH}_{\mathrm{PZC}}$ of $\mathrm{NaOH}-\mathrm{KR}$ (mass of adsorbent = $0.020 \mathrm{~g}$; volume of $\mathrm{MV}$ solution $=10.0 \mathrm{~mL}$; concentration of $\mathrm{MV}=100 \mathrm{mg} \mathrm{L}^{-1}$ ).

this model was thus ruled out from the list of models. Although the simulation plot of the Temkin isotherm model was reasonably good, nevertheless it was also ruled out because it has the highest error values among the models. Comparing the Langmuir and Sips models, the latter has higher $R^{2}$ and lower error values, and therefore, the Langmuir model was ruled out too. Therefore, it can be concluded that the Sips model was the best-chosen model to explain the adsorption process.

Compared to stems, the KR exhibits better affinity toward MV dye, as shown in Table 3. KR also shows much higher $Q_{\max }$ than many natural adsorbents such as leaf-based adsorbents. Treatment with $\mathrm{NaOH}$ enhanced the adsorption capacity of KR by approximately $56 \%$, giving a high $Q_{\max }$ of $551.5 \mathrm{mgg}^{-1}$. Even though the percentage enhancement of $\mathrm{NaOH}-\mathrm{KR}$ is not as high as some reported adsorbents such as leaves of $\mathrm{NaOH}$-modified Artocarpus odoratissimus [45] and pomelo [46], nevertheless, its $Q_{\max }$ value is still considered excellent when compared to surfactant-modified $\mathrm{Fe}_{3} \mathrm{O}_{4}$ magnetic nanoparticles, as well as acid-modified adsorbents, functionalized cellulose, or even synthesized adsorbents. Further, it must be emphasized that the chemical modification in this study is relatively simple and easy to perform, involving stirring the adsorbent in $1.0 \mathrm{M} \mathrm{NaOH}$ at room temperature.
3.4. Effect of $p H$ on $M V$ Removal and Point of Zero Charge $\left(p H_{p z c}\right)$ of $\mathrm{NaOH}-\mathrm{KR}$. Except at strongly acidic $\mathrm{pH}, \mathrm{NaOH}-$ KR exhibited stability under varying $\mathrm{pH}$ conditions and was able to maintain $~ 90 \%$ dye adsorption, as shown in Figure $5(\mathrm{a})$. The point of zero charge $\left(\mathrm{pH}_{\mathrm{PZC}}\right)$ of $\mathrm{NaOH}-$ $\mathrm{KR}$ was determined to be at $\mathrm{pH} 7.1$, as shown in Figure 5(b). Except at a strongly acidic medium of $\mathrm{pH} 2$, $\mathrm{NaOH}-\mathrm{KR}$ was uninfluenced by $\mathrm{pH}$ and was still able to remove almost $90 \% \mathrm{MV}$ when $\mathrm{pH}<\mathrm{pH}_{\mathrm{PZC}}$. A similar trend was reported for Artocarpus odoratissimus stem axis [60]. This is favorable when considering its potential application in wastewater treatment. Generally, the $\mathrm{pH}$ of wastewater is unlikely to be neutral and will fluctuate according to the contaminants in the wastewater. Many adsorbents were reported to reduce their adsorption ability when $\mathrm{pH}$ varies. For example, water hyacinth [55] and $\mathrm{N}$-benzyltriazole derivatized dextran [13] both showed a decrease in adsorption toward MV with increasing $\mathrm{pH}$. Since the removal of MV was comparable at ambient (unadjusted) $\mathrm{pH}$ at 6.4, hence, in this study, it was not necessary to adjust the $\mathrm{pH}$. All subsequent experiments were carried out at ambient $\mathrm{pH}$.

3.5. Effect of Ionic Strength on the Adsorption of $M V$ by $\mathrm{NaOH}-\mathrm{KR}$. Generally, an increase in salt concentration will 


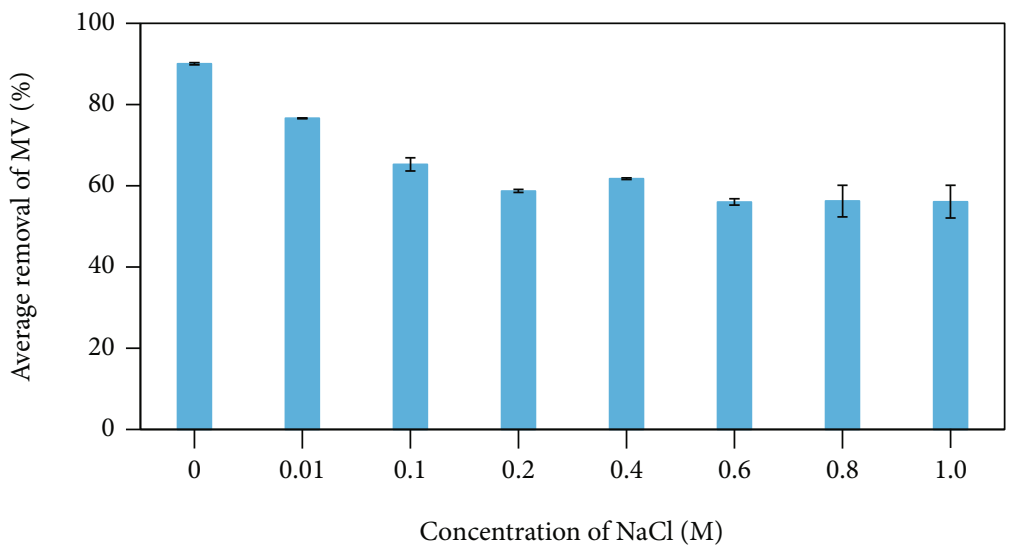

FIGURE 6: The effect of ionic strength of $\mathrm{NaOH}-\mathrm{KR}$ for the removal of $\mathrm{MV}$ dye (mass of adsorbent $=0.020 \mathrm{~g}$; volume of $\mathrm{MV}$ solution = $10.0 \mathrm{~mL}$; concentration of $\mathrm{MV}=100 \mathrm{mg} \mathrm{L}^{-1}$ ).

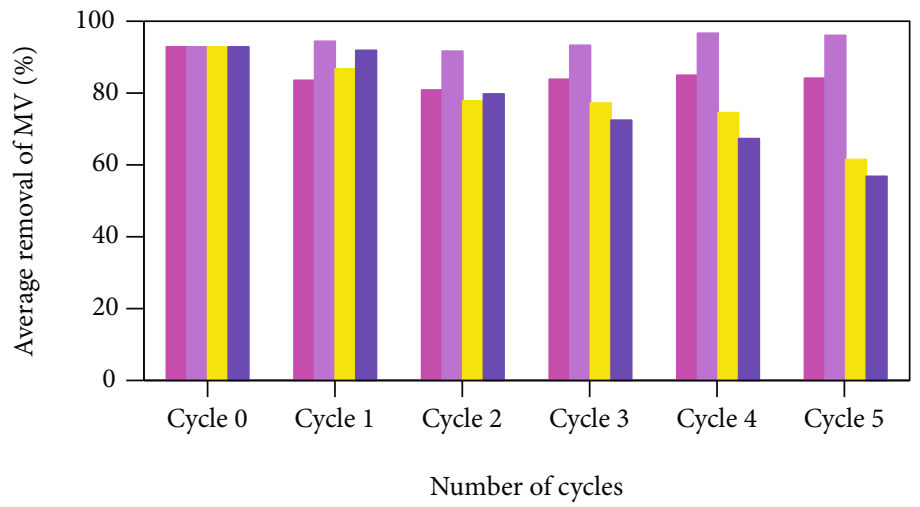

FIgURE 7: Regeneration studies of $\mathrm{NaOH}-\mathrm{KR}$ spent on adsorption of MV for 5 consecutive cycles with acid (pink bar), base (purple bar), water (yellow bar), and control experiment (blue bar) (mass of adsorbent $=0.020 \mathrm{~g}$; concentration of $\mathrm{MV}=100 \mathrm{mg} \mathrm{L}^{-1}$ ).

increase the ionic strength since the salt concentration is directly proportional to the ionic strength. This can affect an adsorbent's ability to remove an adsorbate [61]. As most of the contaminated water usually contains various chemicals, including salts in different amounts, it is therefore crucial to study how ionic strength affects the adsorption process. NaOH-KR showed similar behavior to the untreated KR [25] and Ipomoea aquatica stems [26], where an increase in ionic strength caused a decrease in the adsorption of MV dye. Herein, approximately $34 \%$ reduction was observed at $1.0 \mathrm{M} \mathrm{NaCl}$ concentration (Figure 6).

The accumulation of $\mathrm{Na}^{+}$ions on the adsorbent's surface could lead to an increase in net positive charge and cause electrostatic repulsion of the cationic dye molecules because of the enhancement of hydrophobic-hydrophobic interaction [62]. Hence, there is an observed decrease in the dye removal at higher salt concentrations. Zhang et al. reported that chemical modification could enhance the dispersion properties of an adsorbent by increasing the interaction of adsorbent-adsorbate in the system as well as the adsorption capacity [61]. Furthermore, at high ionic strength, it was mentioned that surface modification could prevent the inherent aggregation of the adsorbent [61]. The ability of
$\mathrm{NaOH}-\mathrm{KR}$ to maintain almost $60 \%$ dye removal at $1.0 \mathrm{M}$ $\mathrm{NaCl}$ is still an attractive feature since the stability of an adsorbent in varying ionic strength is also one of the criteria required for an adsorbent to be used in real-life applications of wastewater.

3.6. Regeneration Studies of NaOH-KR. An adsorbent not only needs to have a high adsorption capacity toward adsorbates, but it must also have the ability to be regenerated and reused. This is because the spent adsorbent, if not being regenerated, needs to be stabilized before disposal into the natural environment as it can lead to fire hazards and loss of potential resources and will release the adsorbed pollutants. Aside from that, if the spent adsorbent can be reused, then it can help lower the operating cost of wastewater treatment plants as well as reduce environmental pollution impact. Not all adsorbents can be regenerated and reused. For example, extracted pectin from durian rind reported about $70 \%$ reduction toward $\mathrm{La}^{3+}$ ions up to the fourth adsorption-desorption cycle [63].

Desorption can be achieved using acid, base, or distilled water which altered the equilibrium of the adsorption process, allowing the adsorbates to move back into the aqueous 

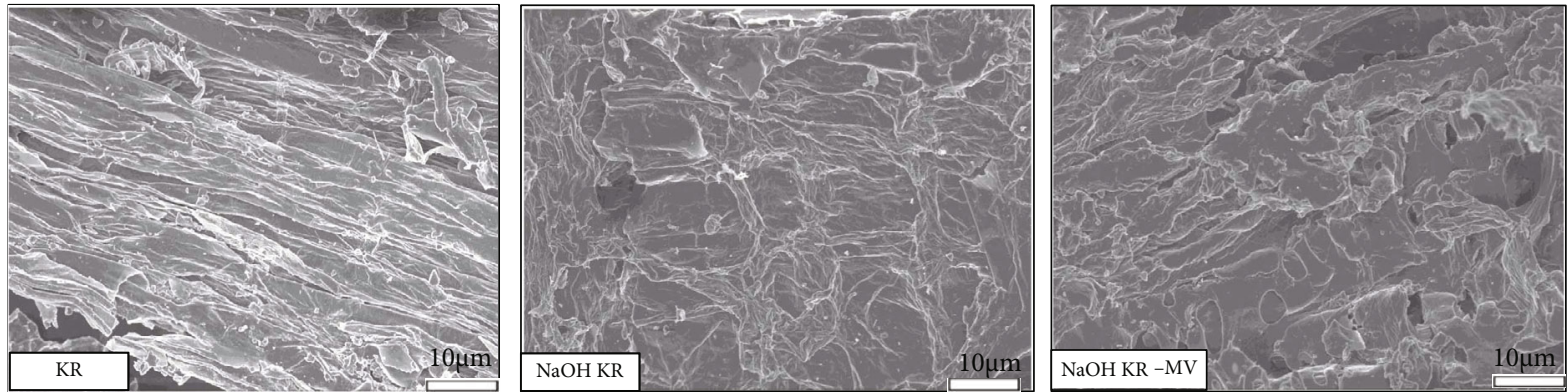

Figure 8: SEM surface morphology of untreated KR, unused $\mathrm{NaOH}-\mathrm{KR}$, and $\mathrm{NaOH}-\mathrm{KR}$ after adsorption of MV, at 1,000x magnification.

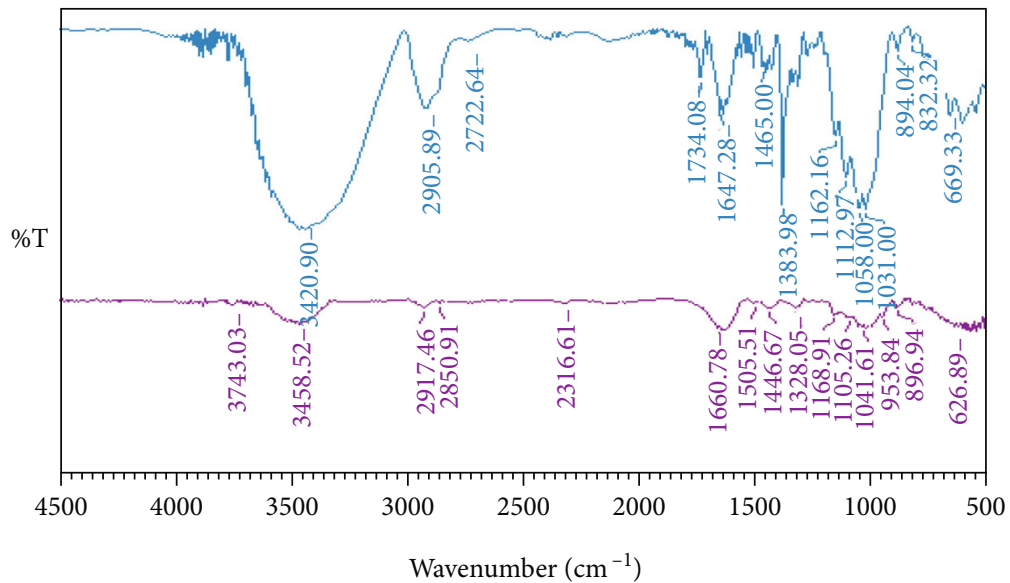

(a)

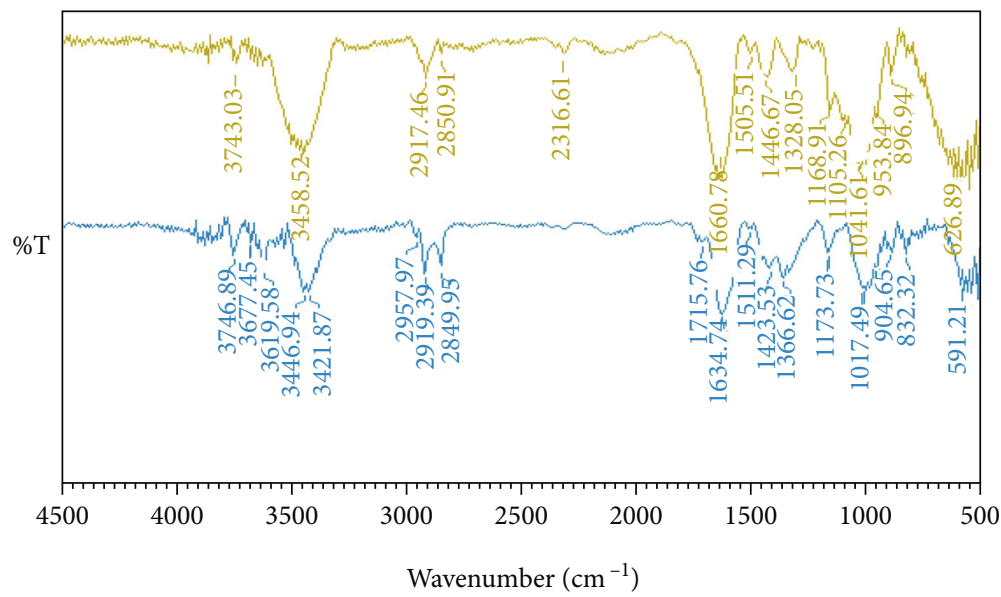

(b)

Figure 9: FT-IR spectra to compare (a) KR (blue) vs. NaOH-KR (Purple) and (b) NaOH-KR before (yellow) and after MV adsorption (blue).

solution [64]. Herein, a reduction of $36 \%$ of MV dye was observed for the control of the spent adsorbent $\mathrm{NaOH}-\mathrm{KR}$, but base washing maintained the removal of $\sim 96 \% \mathrm{MV}$ throughout the five cycles (Figure 7). Thus, the above results confirmed that the modified adsorbent was able to be successfully regenerated and reused while maintaining excellent removal of MV even after five consecutive cycles. This is another attractive feature for its potential application in wastewater treatment since an adsorbent that can be regenerated and reused continuously will be beneficial in terms of financial viability.

3.7. Characterization of $\mathrm{NaOH}-\mathrm{KR}$. Upon modification, there was a distinct change to the surface morphology of the adsorbent, as illustrated in Figure 8. The untreated KR contained stripes with a relatively flat surface, which 
contrasts with the irregular and rough surface of $\mathrm{NaOH}-\mathrm{KR}$. This is possibly due to the strip off the waxes and fats on the adsorbent's surface when treated with $\mathrm{NaOH}$, thereby exposing the underlying adsorption sites of the adsorbent [46]. However, after the dye adsorption, there was no noticeable change on the surface of $\mathrm{NaOH}-\mathrm{KR}$.

Upon base treatment of KR, as shown in Figure 9(a), a very prominent change was observed at $3421 \mathrm{~cm}^{-1}$ where the broad hydroxyl $(-\mathrm{OH})$ group was shifted to $3459 \mathrm{~cm}^{-1}$. Furthermore, C-H stretch and C=C stretch at $2906 \mathrm{~cm}^{-1}$ and $1647 \mathrm{~cm}^{-1}$ were shifted to $2917 \mathrm{~cm}^{-1}$ and $1661 \mathrm{~cm}^{-1}$, respectively. When $\mathrm{NaOH}-\mathrm{KR}$ was treated with $\mathrm{MV}$ dye, as shown in Figure 9(b), the peaks for $\mathrm{O}-\mathrm{H}, \mathrm{C}-\mathrm{H}$, and $\mathrm{C}=\mathrm{C}$ were observed to be shifted, indicating their possible involvement in the adsorption process.

\section{Conclusion}

Unlike many synthetic or modified adsorbents, which require complicated experimental procedures and conditions, herein, $\mathrm{NaOH}$ modification is a very straightforward and simple method which only requires stirring the adsorbent in a base at room temperature. This simple chemical modification of $\mathrm{KR}$ using $1.0 \mathrm{M} \mathrm{NaOH}$ was able to successfully enhance the adsorption capacity toward MV dye by more than 55\% over nonmodified KR. The adsorption equilibrium was achieved within $60 \mathrm{~min}$ and the pseudo-secondorder and Sips models best represent the adsorption process. The effect of ionic strength experiment shows that there is an enhancement of hydrophobic-hydrophobic interaction. The regeneration experiment also demonstrated a high removal rate after five consecutive cycles. With the high adsorption capacity of $\mathrm{NaOH}-\mathrm{KR}$, its stability under varying $\mathrm{pH}$ and salt conditions and its regeneration and reusability properties pave the way for its possible application in wastewater treatment.

\section{Data Availability}

The datasets generated during and/or analyzed during the current study are available in the Mendeley Data repository: Lu, YieChen; Kooh, Muhammad Raziq Rahimi; Lim, Linda Biaw Leng; Priyantha, Namal (2021), "Effective and Simple $\mathrm{NaOH}$-Modification Method to Remove Methyl Violet Dye via Ipomoea aquatica Roots", Mendeley Data, V1, doi:10.17632/7tpdgb585d.1.

\section{Conflicts of Interest}

The authors declare that there is no conflict of interest regarding the publication of this article.

\section{Acknowledgments}

We, the authors, would like to thank the Government of Brunei Darussalam and the Universiti Brunei Darussalam (UBD) for their continuous support.

\section{Supplementary Materials}

The equations of the error functions, isotherm, and kinetics models are available in the supplementary material. The supplementary material for the article is available online. (Supplementary Materials)

\section{References}

[1] F. D. Owa, "Water pollution: sources, effects, control and management," Mediterranean Journal of Social Sciences, vol. 4, p. $65,2013$.

[2] B. A. Kratky, E. T. Fukunaga, J. W. Hylin, and R. T. Nakano, Volcanic air pollution: deleterious effects on tomatoes, Wiley Online Library, 1974.

[3] M. Martınez, E. Fernández, J. Valdés et al., "Chemical evolution and volcanic activity of the active crater lake of Poás volcano, Costa Rica, 1993-1997," Journal of Volcanology and Geothermal Research, vol. 97, no. 1-4, pp. 127-141, 2000.

[4] J. Howe and I. White, "Flooding, Pollution And Agriculture," International Journal of Environmental Studies, vol. 60, no. 1, pp. 19-27, 2003.

[5] P. Gerland, A. E. Raftery, H. ev ikova et al., "World population stabilization unlikely this century," Science, vol. 346, no. 6206, pp. 234-237, 2014.

[6] V. G. Gude and N. Nirmalakhandan, "Sustainable desalination using solar energy," Energy Conversion and Management, vol. 51, no. 11, pp. 2245-2251, 2010.

[7] M. Jaishankar, T. Tseten, N. Anbalagan, B. B. Mathew, and K. N. Beeregowda, "Toxicity, mechanism and health effects of some heavy metals," Interdisciplinary Toxicology, vol. 7, no. 2, pp. 60-72, 2014.

[8] C. R. Holkar, A. J. Jadhav, D. V. Pinjari, N. M. Mahamuni, and A. B. Pandit, "A critical review on textile wastewater treatments: Possible approaches," Journal of Environmental Management, vol. 182, pp. 351-366, 2016.

[9] L. Bulgariu, L. B. Escudero, O. S. Bello et al., "The utilization of leaf-based adsorbents for dyes removal: A review," Journal of Molecular Liquids, vol. 276, pp. 728-747, 2019.

[10] A. G. Adeniyi and J. O. Ighalo, "Biosorption of pollutants by plant leaves: An empirical review," Journal of Environmental Chemical Engineering, vol. 7, no. 3, p. 103100, 2019.

[11] N. Priyantha, L. B. L. Lim, D. T. B. Tennakoon, E. T. Z. Liaw, C. H. Ing, and A. B. Liyandeniya, "Biosorption of cationic dyes on breadfruit (Artocarpus altilis) peel and core," Applied Water Science, vol. 8, pp. 1-11, 2018.

[12] J. Mo, Q. Yang, N. Zhang, W. Zhang, Y. Zheng, and Z. Zhang, "A review on agro-industrial waste (AIW) derived adsorbents for water and wastewater treatment," Journal of Environmental Management, vol. 227, pp. 395-405, 2018.

[13] E. Cho, M. N. Tahir, H. Kim, J.-H. Yu, and S. Jung, "Removal of methyl violet dye by adsorption onto N-benzyltriazole derivatized dextran," RSC Advances, vol. 5, no. 43, pp. 3432734334, 2015.

[14] F. Keyhanian, S. Shariati, M. Faraji, and M. Hesabi, "Magnetite nanoparticles with surface modification for removal of methyl violet from aqueous solutions," Arabian Journal of Chemistry, vol. 9, pp. S348-S354, 2016.

[15] M. A. E. Barakat, R. Kumar, M. K. Seliem et al., "Exfoliated Clay Decorated with Magnetic Iron Nanoparticles for Crystal 
Violet Adsorption: Modeling and Physicochemical Interpretation," Nanomaterials, vol. 10, no. 8, p. 1454, 2020.

[16] P. K. Singh, S. K. Tiwari, N. Rai, K. Rai, and M. Singh, “Antioxidant and phytochemical levels and their interrelation in stem and leaf extract of water spinach (Ipomea aquatica)," Indian Journal of Agricultural Sciences, vol. 86, pp. 347-354, 2016.

[17] K. Nagendra Prasad, G. R. Shivamurthy, and S. M. Aradhya, "Ipomoea aquatica, an underutilized green leafy vegetable: a review." International Journal of Botany, vol. 4, pp. 123-129, 2008.

[18] Q. Zhang, V. Achal, Y. Xu, and W.-N. Xiang, “Aquaculture wastewater quality improvement by water spinach (Ipomoea aquatica Forsskal) floating bed and ecological benefit assessment in ecological agriculture district," Aquacultural Engineering, vol. 60, pp. 48-55, 2014.

[19] A. Endut, A. Jusoh, N. Ali, W. Wan Nik, and A. Hassan, "Effect of flow rate on water quality parameters and plant growth of water spinach (Ipomoea aquatica) in an aquaponic recirculating system," Desalination and Water Treatment, vol. 5, no. 1-3, pp. 19-28, 2009.

[20] M. B. Kurade, J.-Q. Xiong, S. P. Govindwar et al., "Uptake and biodegradation of emerging contaminant sulfamethoxazole from aqueous phase using Ipomoea aquatica," Chemosphere, vol. 225, pp. 696-704, 2019.

[21] L. Bedabati Chanu and A. Gupta, "Phytoremediation of lead using Ipomoea aquatica Forsk. in hydroponic solution," Chemosphere, vol. 156, pp. 407-411, 2016.

[22] A. Weerasinghe, S. Ariyawnasa, and R. Weerasooriya, "Phytoremediation potential of Ipomoea aquatica for $\mathrm{Cr}(\mathrm{VI})$ mitigation," Chemosphere, vol. 70, no. 3, pp. 521-524, 2008.

[23] V. S. Nguyen and M. L. Nguyen, "Removal of cadmium from aqueous solution by spinach (Ipomoea aquatica)," Global Journal of Environmental Research, vol. 5, pp. 1-7, 2011.

[24] K.-S. Wang, L.-C. Huang, H.-S. Lee, P.-Y. Chen, and S.H. Chang, "Phytoextraction of cadmium by Ipomoea aquatica (water spinach) in hydroponic solution: Effects of cadmium speciation," Chemosphere, vol. 72, no. 4, pp. 666-672, 2008.

[25] Y. C. Lu, N. Priyantha, L. B. L. Lim, A. H. Mahadi, and N. A. M. Zain, "Ipomoea aquatica root as a new potential adsorbent to remove methyl violet $2 \mathrm{~b}$ dye in simulated dye contaminated wastewater," Desalination and Water Treatment, vol. 197, pp. 368-378, 2020.

[26] T. L. Kua, M. R. R. Kooh, M. K. Dahri, N. A. H. M. Zaidi, Y. C. Lu, and L. B. L. Lim, "Aquatic plant, Ipomoea aquatica, as a potential low-cost adsorbent for the effective removal of toxic methyl violet 2B dye," Applied Water Science, vol. 10, pp. 243-243, 2020.

[27] T. Tarawou, D. Wankasi, and M. Horsfall, "Column removal of methylene blue using activated carbon derived from water spinach (Ipomoea aquatica)," International Journal of Biological and Chemical Sciences, vol. 4, no. 3, 2010.

[28] Y. Lu, N. Priyantha, and L. B. L. Lim, "Ipomoea aquatica roots as environmentally friendly and green adsorbent for efficient removal of Auramine O dye," Surfaces and Interfaces, vol. 20, pp. 100543-100543, 2020.

[29] M. R. R. Kooh, L. B. L. Lim, M. K. Dahri, L. H. Lim, and J. M. R. Sarath Bandara, "Azolla pinnata: An Efficient Low Cost Material for Removal of Methyl Violet 2B by Using Adsorption Method," Waste and Biomass Valorization, vol. 6, no. 4, pp. 547-559, 2015.
[30] M. R. R. Kooh, M. K. Dahri, and L. B. L. Lim, "Removal of methyl violet $2 \mathrm{~B}$ dye from aqueous solution using Nepenthes rafflesiana pitcher and leaves," Applied Water Science, vol. 7, no. 7, pp. 3859-3868, 2017.

[31] W. Astuti and D. M. Fatin, "Adsorption of methyl violet dye by thermally modified ceiba pentandra sawdust," Jurnal Bahan Alam Terbarukan, vol. 6, no. 2, pp. 183-189, 2017.

[32] Y. Li, H. Xiao, M. Chen, Z. Song, and Y. Zhao, "Absorbents based on maleic anhydride-modified cellulose fibers/diatomite for dye removal," Journal of Materials Science, vol. 49, no. 19, pp. 6696-6704, 2014.

[33] S. Lagergren and K. Sven, "About the theory of so-called adsorption of soluble substances," Vetenskapsakad. Handl, vol. 24, pp. 1-39, 1898.

[34] Y. S. Ho and G. McKay, "Sorption of dye from aqueous solution by peat," Chemical Engineering Journal, vol. 70, no. 2, pp. 115-124, 1998.

[35] M. J. D. Low, "Kinetics of Chemisorption of Gases on Solids," Chemical Reviews, vol. 60, no. 3, pp. 267-312, 1960.

[36] L. Largitte and R. Pasquier, "A review of the kinetics adsorption models and their application to the adsorption of lead by an activated carbon," Chemical Engineering Research and Design, vol. 109, pp. 495-504, 2016.

[37] M. A. Hubbe, S. Azizian, and S. Douven, "Implications of apparent pseudo-second-order adsorption kinetics onto cellulosic materials: A review," BioResources, vol. 14, no. 3, pp. 7582-7626, 2019.

[38] E. I. Unuabonah, M. O. Omorogie, and N. A. Oladoja, Modeling in Adsorption: Fundamentals and Applications, Elsevier Inc., 2019.

[39] I. Langmuir, "The constitution and fundamental properties of solids and liquids. Ii. Liquids.1," Journal of the American Chemical Society, vol. 39, no. 9, pp. 1848-1906, 1917.

[40] H. M. F. Freundlich, "Over the adsorption in solution," The Journal of Physical Chemistry A, vol. 57, pp. 1100-1107, 1906.

[41] M. I. Temkin, "Kinetics of ammonia synthesis on promoted iron catalysts," Acta physiochim. URSS, vol. 12, pp. 327-356, 1940.

[42] O. J. D. L. Redlich and D. L. Peterson, "A Useful Adsorption Isotherm," Journal of Physical Chemistry, vol. 63, no. 6, p. 1024, 1959.

[43] R. Sips, "On the Structure of a Catalyst Surface," The Journal of Chemical Physics, vol. 16, no. 5, pp. 490-495, 1948.

[44] C. R. Girish, "Various isotherm models for multicomponent adsorption: A review," International Journal of Civil Engineering and Technology, vol. 8, pp. 80-86, 2017.

[45] L. B. L. Lim, N. Priyantha, and N. A. H. Mohamad Zaidi, "A superb modified new adsorbent, Artocarpus odoratissimus leaves, for removal of cationic methyl violet 2B dye," Environmental Earth Sciences, vol. 75, no. 16, pp. 1179-1179, 2016.

[46] Y. Lu, L. B. L. Lim, and N. Priyantha, "Chemical modification of pomelo leaves as a simple and effective way to enhance adsorption toward methyl violet dye," Desalination and Water Treatment, vol. 197, pp. 379-391, 2020.

[47] A. Guzmán-Vargas, E. Lima, G. A. Uriostegui-Ortega, M. A. Oliver-Tolentino, and E. E. Rodríguez, "Adsorption and subsequent partial photodegradation of methyl violet $2 \mathrm{~B}$ on $\mathrm{Cu} / \mathrm{Al}$ layered double hydroxides," Applied Surface Science, vol. 363, pp. 372-380, 2016.

[48] L. B. L. Lim, N. Priyantha, X. H. Bong, and N. A. H. M. Zaidi, "Enhancement of adsorption characteristics of Methyl violet 
2B dye through $\mathrm{NaOH}$ treatment of Cucumis melo var. cantalupensis (rock melon) skin," Desalination and Water Treatment, vol. 180, pp. 336-348, 2020.

[49] A. T. M. Din and B. H. Hameed, "Adsorption of methyl violet dye on acid modified activated carbon: isotherms and thermodynamics," Journal of Applied Sciences in Environmental Sanitation, vol. 5, pp. 161-170, 2010.

[50] M. Khairud Dahri, C. Hei Ing, L. Lim, N. Priyantha, and C. Chin Mei, "Cempedak durian (Artocarpus sp.) peel as a biosorbent for the removal of toxic methyl violet $2 \mathrm{~B}$ from aqueous solution," Korean Chemical Engineering Research, vol. 53, pp. 576-583, 2015.

[51] M. Din, K. Ijaz, and K. Naseem, "Biosorption potentials of acid modified Saccharum bengalense for removal of methyl violet from aqueous solutions," Chemical Industry and Chemical Engineering Quarterly, vol. 23, pp. 399-409, 2017.

[52] S. M. Musyoka, H. Mittal, S. B. Mishra, and J. C. Ngila, "Effect of functionalization on the adsorption capacity of cellulose for the removal of methyl violet," International Journal of Biological Macromolecules, vol. 65, pp. 389-397, 2014.

[53] Y. Tang, Q. Zhou, Y. Zhao, and Y. Peng, "Efficient removal of methyl violet from aqueous solution by a low-cost adsorbent-C. camphorafallen leaves powder," Journal of Dispersion Science and Technology, vol. 38, no. 8, pp. 1135-1141, 2017.

[54] Y. Tang, Y. Li, Y. Zhao, Q. Zhou, and Y. Peng, "Enhanced removal of methyl violet using $\mathrm{NaOH}$-modified C. camphora leaves powder and its renewable adsorption," Desalination and Water Treatment, vol. 98, pp. 306-314, 2017.

[55] K. Malviya, C. Parashar, S. Dixit, and S. Kaur, "Aquatic plant, Ipomoea aquatica, as a potential low-cost adsorbent for the effective removal of toxic methyl violet $2 \mathrm{~B}$ dye," International Journal of ChemTech Research, vol. 10, pp. 369-374, 2017.

[56] K. Samal, N. Raj, and K. Mohanty, "Saponin extracted waste biomass of Sapindus mukorossi for adsorption of methyl violet dye in aqueous system," Surfaces and Interfaces, vol. 4, pp. 166-174, 2019.

[57] Y. Kim, J. Bae, H. Park, J.-K. Suh, Y.-W. You, and H. Choi, "Adsorption dynamics of methyl violet onto granulated mesoporous carbon: Facile synthesis and adsorption kinetics," Water Research, vol. 101, pp. 187-194, 2016.

[58] L. B. L. Lim, N. Priyantha, Y. Lu, and N. A. H. M. Zaidi, "Effective removal of methyl violet dye using pomelo leaves as a new low-cost adsorbent," Desalination and Water Treatment, vol. 110, pp. 264-274, 2018.

[59] L. B. L. Lim, N. Priyantha, C. M. Chan, D. Matassan, H. I. Chieng, and M. R. R. Kooh, "Investigation of the sorption characteristics of water lettuce (WL) as a potential low-cost biosorbent for the removal of methyl violet 2B," Desalination and Water Treatment, vol. 57, no. 18, pp. 8319-8329, 2016.

[60] M. R. R. Kooh, M. K. Dahri, and L. B. L. Lim, "Removal of the methyl violet $2 \mathrm{~B}$ dye from aqueous solution using sustainable adsorbent Artocarpus odoratissimus stem axis," Applied Water Science, vol. 7, no. 7, pp. 3573-3581, 2017.

[61] Y. Zhang, C. Zhu, F. Liu, Y. Yuan, H. Wu, and A. Li, "Effects of ionic strength on removal of toxic pollutants from aqueous media with multifarious adsorbents: A review," Science of the Total Environment, vol. 646, pp. 265-279, 2019.

[62] Y. Hu, T. Guo, X. Ye et al., "Dye adsorption by resins: Effect of ionic strength on hydrophobic and electrostatic interactions," Chemical Engineering Journal, vol. 228, pp. 392-397, 2013.
[63] E. Kusrini, W. Wicaksono, C. Gunawan, N. Z. A. Daud, and A. Usman, "Kinetics, mechanism, and thermodynamics of lanthanum adsorption on pectin extracted from durian rind," Journal of Environmental Chemical Engineering, vol. 6, no. 5, pp. 6580-6588, 2018.

[64] R. Shamey and X. Zhao, Modelling, simulation and control of the dyeing process, Elsevier, 2014. 